\title{
First-line Osimertinib for Poor Performance Status Patients With EGFR Mutation-positive Non-small Cell Lung Cancer: A Prospective Observational Study
}

Satoshi Igawa ( $\sim$ igawa@kitasato-u.ac.jp)

Department of Respiratory Medicine, Kitasato University School of Medicine https://orcid.org/00000002-7527-8766

\section{Tomoya Fukui}

Kitasato University School of Medicine

Masashi Kasajima

Kitasato University School of Medicine

\section{Taihei Ono}

Kitasato University School of Medicine

\section{Takahiro Ozawa}

Kitasato University School of Medicine

\section{Mikiko Kakegawa}

Kitasato University School of Medicine

\section{Seiichiro Kusuhara}

Kitasato University School of Medicine

\section{Takashi Sato}

Kitasato university School of Medicine

\section{Yoshiro Nakahara}

Kitasato University School of Medicine

Mitsufuji Hisashi

Kitasato university School of Nursing

Jiichro Sasaki

Kitasato University School of Medicine

Katsuhiko Naoki

Kitasato University School of Medicine

\section{Research Article}

Keywords: Non-small cell lung carcinoma, poor performance status, osimertinib, efficacy 
Posted Date: October 18th, 2021

DOl: https://doi.org/10.21203/rs.3.rs-976126/v1

License: (c) (i) This work is licensed under a Creative Commons Attribution 4.0 International License. Read Full License

Version of Record: A version of this preprint was published at Investigational New Drugs on November 22nd, 2021. See the published version at https://doi.org/10.1007/s10637-021-01195-2. 


\section{Abstract}

Objective: The clinical outcomes of poor performance status (PS) patients with epidermal growth factor receptor (EGFR)-mutated non-small cell lung cancer (NSCLC) who are treated with osimertinib as a firstline treatment have not been sufficiently evaluated. This study aimed to assess the efficacy and safety of osimertinib in chemotherapy-naive and poor PS (2 or more) patients with NSCLC harboring sensitive EGFR mutations.

Materials and Methods: We assessed the clinical effects of osimertinib as a first-line treatment for patients with poor PS NSCLC with an exon 19 deletion or exon 21 L858R mutation in EGFR. All patients were administered osimertinib ( $80 \mathrm{mg} /$ day) as the initial treatment.

Results: Sixteen patients (nine women and seven men) who were treated between August 2018 and July 2021 were included in this study; their median age was 78 years. The overall objective response rate was $56.3 \%$. The median progression-free survival (PFS) of the entire patient population was 10.5 months and the PS score improved in 8 of 16 patients (50\%). The most common adverse event was acneiform rash $(42 \%)$, followed by diarrhea (36\%) and paronychia (36\%); none of these were of grade $\geq 3$. Interstitial lung disease occurred in 2 patients (12.5\%); however, no treatment-related deaths occurred.

Conclusion: Considering the findings of this study, osimertinib appears to be an effective and safe treatment option for patients with poor PS and advanced NSCLC harboring sensitive EGFR mutations. To obtain conclusive results, further studies with larger cohorts are warranted.

\section{Introduction}

Lung cancer is one of the main causes of cancer-related deaths, and non-small cell lung cancer (NSCLC) accounts for approximately $85 \%$ of all lung cancer cases [1]. Recently, epidermal growth factor receptor (EGFR) tyrosine kinase inhibitors (TKIs) have markedly improved the prognosis of patients with NSCLC harboring EGFR-activating mutations. Approximately $70 \%$ of NSCLC patients are diagnosed at advanced stages, and NSCLC is a common cause of cancer-related mortality [2]. EGFR gene mutations are detected in approximately $30 \%$ of East Asian patients with NSCLC [3, 4]. Based on the positive results from phase III trials [5-12], EGFR-TKIs have been administered to such patients, and several EGFR-TKIs are currently approved as first-line treatments for EGFR mutation-positive NSCLC in Japan. These include the first-, second-, and third-generation TKIs: erlotinib and gefitinib, afatinib and dacomitinib, and osimertinib, respectively. We have previously reported real-world data, indicating the efficacy of first- and secondgeneration TKIs for patients with EGFR mutation-positive NSCLC [13-15]. It was reported that osimertinib had survival benefits compared to first-generation EGFR-TKIs, with not only a significantly superior survival time, but also a less toxic profile in the FLAURA trial [12]. This resulted in its approval as a standard first-line treatment for EGFR-mutated NSCLC, indicating that its administration may be a feasible intervention for patients with poor performance status (PS). PS is an important prognostic and predictive factor in most cancer treatments. Previous studies have supported the use of first-and second- 
generation EGFR-TKIs, such as gefitinib and afatinib, as a first-line treatment for patients with NSCLC and poor PS harboring sensitive EGFR mutations [16-18]. Several studies have indicated that osimertinib could be beneficial in poor PS patients with EGFR T790M mutation-positive NSCLC whose disease has progressed following first-line EGFR-TKI treatment [19-21]. However, existing data are insufficient to determine the efficacy of osimertinib in chemo-naïve patients with NSCLC and poor PS.

Hence, the aim of this prospective observational study was to evaluate the efficacy and safety of first-line osimertinib for patients with poor PS and advanced NSCLC harboring sensitive EGFR mutations.

\section{Materials And Methods Patient selection}

We conducted a prospective observational cohort study at Kitasato University Hospital between August 2018 and July 2021 to evaluate the efficacy and safety of osimertinib in patients with EGFR mutationpositive advanced NSCLC with a poor PS score (2 or more). The eligibility criteria were as follows: histologically or cytologically confirmed NSCLC harboring either an exon 19 deletion or exon 21 L858R mutation in EGFR, stage IIIB-IV disease with postoperative recurrence according to the new Union for International Cancer Control criteria (version 8), having at least one measurable lesion according to the Response Evaluation Criteria in Solid Tumors (RECIST) 1.1 [22], and the ability to receive oral treatment. Patient characteristics, including age at diagnosis, sex, Eastern Cooperative Oncology Group PS at the start of the osimertinib treatment, smoking status, clinical stage, tumor histology, and brain metastasis status, were identified via chart review. The PS score of each patient was assessed by two investigators (S.I. and M.K.). All patients provided written informed consent prior to enrollment.

\section{Treatment and Response assessment}

All patients received a single daily dose $(80 \mathrm{mg})$ of osimertinib. Treatment was continued until disease progression or the occurrence of unacceptable adverse events. After initiating the osimertinib treatment, computed tomography of the chest and abdomen was performed every 2 to 3 months or more frequently, if necessary. Positron emission tomography, bone scintigraphy, computed tomography, or magnetic resonance imaging of the cranium were performed at 6-month intervals or whenever patients had significant symptoms associated with tumor lesions. The response to treatment was re-evaluated by two investigators (S.I. and M.S.), and the treatment efficacy was assessed using the RECIST. The best overall response and maximum tumor control were recorded as tumor responses. Radiation therapy for patients with pre-existing brain metastasis prior to osimertinib treatment was performed at the discretion of the physician in charge. Among the patients with pre-existing brain metastasis, computed tomography or magnetic resonance imaging of the head was performed every 6 months or more frequently, if necessary.

\section{Toxicity assessment and dose modification}


Toxicities were graded according to the National Cancer Institute Common Toxicity Criteria (version 5). The physical conditions, symptoms, blood tests, and chest X-rays of patients were evaluated throughout the osimertinib treatment at the discretion of the physician in charge. Any interruption, discontinuation, or dose reduction of osimertinib caused by toxicity was done at the discretion of the physician in charge.

\section{Statistical analysis}

Progression-free survival (PFS) was defined as the interval between the date of osimertinib therapy initiation and that of disease progression or death; if neither occurred, the patient was censored on the date of the last follow-up examination. Survival curves were plotted using the Kaplan-Meier method, and differences according to brain metastasis status were analyzed using the log-rank test. Statistical significance was set at $p<0.05$. All statistical analyses were performed using SPSS version 28.0 for Windows (IBM Corp., Armonk NY, USA).

\section{Results}

\section{Patient characteristics}

Sixteen patients with NSCLC who were treated with osimertinib between August 2018 and January 2021 were included in the final analysis. As shown in Table 1, the median patient age was 78 years, and $56 \%$ were men. Fourteen and two patients had a PS score of 2 and 3, respectively. Fourteen patients had adenocarcinomas, two had adeno-squamous carcinomas, 63\% had an EGFR exon 19 deletion, and 38\% had an L858R point mutation. Four patients with postoperative recurrence were included in the entire patient population. Nine patients $(56 \%)$ had brain metastasis before osimertinib treatment, including two patients who received radiotherapy for brain metastasis prior to osimertinib treatment.

\section{Overall efficacy}

Table 2 presents the objective tumor responses. An objective response was obtained in 9 of the 16 patients, indicating an objective response rate of 56.3\% (95\% confidence interval [CI]: $47.1 \%-78.0 \%$ ). The cut-off date for survival analysis was September 2021, and the median follow-up period by that date was 18.7 months. The median PFS of the entire patient population was 10.5 months (95\% Cl: $2.8-18.2$ months; Figure 1). The median PFS in patients with versus without pre-existing brain metastasis was 13.7 months (95\% Cl: 4.4-23.0 months) and 10.5 months (95\% Cl: 5.6-15.4 months), respectively; the difference was not significant $(P=0.77$, Figure 2$)$. Among the nine patients with pre-existing brain metastasis prior to osimertinib treatment, disease progression following osimertinib treatment owing to the progression of intracranial lesion was observed in 2 patients (22.2\%), as follows; aprogression of preexisting brain metastasis in one patient and leptomeningeal carcinomatosis in another patient. In the two patients who received radiotherapy for brain metastasis prior to osimertinib treatment, partial responses were observed and they remained on osimertinib without disease progression at the cut-off date for survival analysis. Among the seven patients who did not have pre-existing intracranial lesions before osimertinib treatment, disease progression due to the occurrence of a new brain metastasis was observed 
in one patient (14.3\%). Eleven patients discontinued osimertinib treatment because of disease progression, among whom six patients received second-line treatments (carboplatin plus pemetrexed [ $\mathrm{n}=$ 3], other EGFR-TKIs [ $=2$ ], and pembrolizumab [ $=1]$ ). No patient continued osimertinib treatment beyond disease progression.

The overall changes in PS scores during osimertinib treatment in all patients are shown in Figure 3 . The PS score improved to a score of 1 in 8 out of 16 patients (50\%), including the improvement of the PS score to a score of 1 from a score of 3 in two patients who had a partial response to osimertinib treatment.

\section{Toxicities}

The toxicity of osimertinib was evaluated in all patients. The main adverse events observed during treatment are presented in Table 3. The most common ones were rash acneiform (7 patients [44\%], none with a grade $\geq 3$ ), diarrhea ( 6 patients [38\%], none with a grade $\geq 3$ ), and paronychia ( 6 patients [36\%], none with a grade $\geq 3$ ). Interstitial lung disease (ILD) was detected in two patients (12.5\%), one of whom had grade 3 ILD. Furthermore, one patient developed grade 3 fatigue, and another developed grade 3 anemia. Six patients (37.5\%) required an osimertinib dose reduction due to adverse events. Osimertinib administration was discontinued in two patients (12.5\%) owing to ILD (from which they recovered after corticosteroid therapy and no recrudescence was observed). None of the patients discontinued osimertinib therapy because of other adverse events.

The duration of osimertinib treatment until disease progression or cessation owing to adverse events in individual patients is summarized in Figure 4.

\section{Discussion}

In a phase III study (FLAURA), osimertinib was found to significantly prolong the PFS compared with gefitinib or erlotinib in NSCLC patients harboring sensitive EGFR mutations [12]. Moreover, the osimertinib group of the Japanese subset of the FLAURA study had a PFS of 19.1 months, indicating the efficacy of osimertinib as first-line therapy in the Japanese population [23]. However, the poor PS population was not included in the FLAURA study, and existing data remain insufficient to determine the efficacy of osimertinib as first-line treatment in patients with poor PS. We found, for the first time, that first-line treatment with osimertinib provided a response rate of $56.3 \%$ and a median PFS of 10.5 months in this patient population.

Osimertinib treatment for patients with poor PS could be beneficial and clinically meaningful, considering that cytotoxic chemotherapy provides limited benefits to NSCLC patients with a PS score of 2 and that, currently, the only option for patients with PS scores of 3-4 is best supportive care. Regarding the changes in PS scores during osimertinib treatment, the PS scores were improved in 8 of 16 patients (50\%), including notable improvements to a score of 1 from a score of 3 in two patients who had a partial response to osimertinib. In general, the preservation of the PS is indispensable for connecting patients to 
post-treatment with sequential chemotherapy, which prolongs patient survival. Of the 11 patients with disease progression on osimertinib, 6 patients (55\%) received second-line chemotherapy based on the preservation of PS with the osimertinib treatment. Notably, three of these patients received carboplatin plus pemetrexed, suggesting the clinical usefulness of osimertinib in patients with poor PS.

The incidence of drug-induced ILD in the Japanese subgroup of the FLAURA study was approximately $1.8 \%$ in those administered gefitinib but was $12.3 \%$ in those administered osimertinib [23]. Inoue et al. reported the safety of gefitinib for EGFR-TKI-naive patients with poor PS [16], showing that the incidence of ILD was $3.3 \%$. A phase II study reported that the incidence of ILD induced by osimertinib was observed in $17 \%$ of patients with poor PS with EGFR T790M mutation-positive advanced NSCLC who were pretreated with other EGFR-TKIs [21]. Additionally, ILD due to osimertinib was observed in two patients (12\%), indicating that ILD incidence may be high in poor PS patients treated with osimertinib.Meanwhile, the patients with drug-induced ILD recovered after corticosteroid therapy, and no mortality due to druginduced ILD was observed in our study. A previous study demonstrated that $80 \%$ of patients with ILD complicated by osimertinib recovered, and that the mortality from drug-induced ILD was lower in those administered osimertinib (11.8\%) than in those treated with gefitinib (38.9\%) and erlotinib (35.6\%) [24], suggesting that recovery from ILD is mostly expected in patients receiving osimertinib.

The proportion of patients with brain metastases was $56 \%$ here, and most patients initially received systemic chemotherapy with osimertinib, except for two patients who received radiotherapy for brain metastasis prior to osimertinib treatment. As for patients with pre-existing brain metastases prior to osimertinib treatment, the FLAURA study [12] showed that central nervous system progression was less frequent in patients receiving osimertinib than in those receiving first-generation EGFR-TKIs, such as gefitinib and erlotinib (6\% vs. $15 \%$ ). Other studies have shown that osimertinib is effective for both systemic and brain metastatic lesions in patients with pre-existing brain metastases $[25,26]$. Here, no statistically significant difference was observed in PFS according to the presence or absence of preexisting brain metastases; as such, our findings were consistent with those of the above studies. Therefore, it may be reasonable to mention that osimertinib is expected to be effective for brain metastatic lesions in both poor and good PS populations.

Table 4 provides a summary of previous studies on patients with poor PS who were treated with first-line EGFR-TKIs, showing that the response rate found here was identical to that found in previous studies of other EGFR-TKIs; however, the PFS of our patients appeared to be longer than that of patients who were treated with other EGFR-TKIs.

This study has several limitations. First, the cohort size is very small, and the study was performed at a single institution. Second, we did not include patients with a PS score of 4 , for which the clinical efficacy and safety of osimertinib remains unclear. Third, the evaluation of the PS is very difficult. While the PS score of each patient was assessed by two investigators in our study, bias arising from the subjectivity of investigators might not be completely excluded. Fourth, while the individuals included in this study had poor PS, their quality of life was not evaluated. 
Considering our findings, osimertinib appears to be an effective and safe treatment option for patients with poor PS and advanced NSCLC harboring sensitive EGFR mutations. To obtain conclusive results, further studies with larger cohorts are warranted.

\section{Declarations}

Ethics approval and consent to participate: All procedures performed in studies involving human participants were in accordance with the ethical standards of the institutional and/or national research committee and with the 1964 Helsinki declaration and its later amendments or comparable ethical standards. This study was approved by the Institutional Ethics Review Board of Kitasato University Hospital. All patients provided written informed consent prior to enrollment.

Consent for publication: All authors the study gave consent to publication of this study.

Funding: There was no funding to declare.

Availability of data and material: The datasets generated and/or analyzed during the current study are available from the corresponding author upon reasonable request.

\section{Competing interests}

There was no competing interest to declare.

Author contributions: All authors contributed to the study conception and design. Data collection was performed by all authors, and analysis was performed by SI and MK. The first draft of the manuscript was written by SI and KN. All authors commented on versions of the manuscript. All authors read and approved the final version of the manuscript.

Acknowledgements: We gratefully thank the staff members of the Department of Respiratory Medicine, Kitasato University School of Medicine, for their suggestions and assistance.

\section{Compliance with Ethical Standards}

\section{Disclosure of potential conflicts of interest}

The authors declare that they have no conflict of interest.

\section{Research involving Human Participants and/or Animals}

Not applicable.

\section{Informed consent}

Informed consent was obtained from all individual participants included in the study. 


\section{References}

1. Molina JR, Yang P, Cassivi SD, Schild SE, Adjei AA (2008) Non-small-cell lung cancer. Epidemiology, risk factors, treatment, and survivorship. Mayo Clin Proc 83:584-594. DOI:

10

\section{$.4065 / 83.5 .584$}

2. Siegel R, Naishadham D, Jemal A (2012) Cancer statistics, 2012. CA Cancer J Clin 62:10-29. DOI:10.3322/caac.20138

3. Lynch TJ, Bell DW, Sordella R, Gurubhagavatula S, Okimoto RA, Brannigan BW, Harris PL, Haserlat SM, Supko JG, Haluska FG, Louis DN, Christiani DC, Settleman J, Haber DA (2004) Activating mutations in the epidermal growth factor receptor underlying responsiveness of non-small-cell lung cancer to gefitinib. N Engl J Med 350:2129-2139. DOI:10.1056/NEJMoa040938

4. Shigematsu H, Lin L, Takahashi T, Nomura M, Suzuki M, Wistuba II, Fong KM, Lee H, Toyooka S, Shimizu N, Fujisawa T, Feng Z, Roth JA, Herz J, Minna JD, Gazdar AF (2005) Clinical andbiological features associated with epidermal growth factor receptor gene mutations in lung cancers. $J$ Natl Cancer Inst 97:339-346. DOI:10.1093/jnci/dji055

5. Maemondo M, Inoue A, Kobayashi K, Sugawara S, Oizumi S, Isobe H, Gemma A, Harada M, Yoshizawa H, Kinoshita I, Fujita Y, Okinaga S, Hirano H, Yoshimori K, Harada T, Ogura T, Ando M, Miyazawa H, Tanaka T, Saijo Y, Hagiwara K, Morita S, Nukiwa T, North-East Japan Study Group (2010) Gefitinib or chemotherapy for non-small-cell lung cancer with mutated EGFR. N Engl J Med 362:2380-2388. DOI:10.1056/NEJMoa0909530

6. Mitsudomi T, Morita S, Yatabe Y, Negoro S, Okamoto I, Tsurutani J, Seto T, Satouchi M, Tada H, Hirashima T, Asami K, Katakami N, Takada M, Yoshioka H, Shibata K, Kudoh S, Shimizu E, Saito H, Toyooka S, Nakagawa K, Fukuoka M, West Japan Oncology Group (2010) Gefitinib versus cisplatin plus docetaxel in patients with non-small-cell lung cancer harbouring mutations of the epidermal growth factor receptor (WJTOG3405): An open label, randomised phase 3 trial. Lancet Oncol 11:121-128. DOI:10.1016/S1470-2045(09)70364-X

7. Rosell R, Carcereny E, Gervais R, Vergnenegre A, Massuti B, Felip E, Palmero R, Garcia-Gomez R, Pallares C, Sanchez JM, Porta R, Cobo M, Garrido P, Longo F, Moran T, Insa A, De Marinis F, Corre R, Bover I, Illiano A, Dansin E, de Castro J, Milella M, Reguart N, Altavilla G, Jimenez U, Provencio M, Moreno MA, Terrasa J, Muñoz-Langa J, Valdivia J, Isla D, Domine M, Molinier O, Mazieres J, Baize N, Garcia-Campelo R, Robinet G, Rodriguez-Abreu D, Lopez-Vivanco G, Gebbia V, Ferrera-Delgado L, Bombaron P, Bernabe R, Bearz A, Artal A, Cortesi E, Rolfo C, Sanchez-Ronco M, Drozdowskyj A, Queralt C, de Aguirre I, Ramirez JL, Sanchez JJ, Molina MA, Taron M, Paz-Ares L (2012) Erlotinib versus standard chemotherapy as first-line treatment for European patients with advanced EGFR mutation-positive non-smallcell lung cancer (EURTAC): A multicentre, open-label, randomised phase 3 trial. Lancet Oncol 13:239-246. DOI:10.1016/S1470-2045(11)70393-X

8. Zhou C, Wu YL, Chen G, Feng J, Liu X, Wang C, Zhang S, Wang J, Zhou S, Ren S, Lu S, Zhang L, Hu C, Hu C, Luo Y, Chen L, Ye M, Huang J, Zhi X, Zhang Y, Xiu Q, Ma J, Zhang L, You C (2011) Erlotinib 
versus chemotherapy as first-line treatment for patients with advanced EGFR mutation-positive nonsmall-cell lung cancer (OPTIMAL, CTONG-0802): A multicentre, openlabel, randomised, phase 3 study. Lancet Oncol 12:735-742. DOI:10.1016/S1470-2045(11)70184-X

9. Sequist LV, Yang JC, Yamamoto N, O’Byrne K, Hirsh V, Mok T, Geater SL, Orlov S, Tsai CM, Boyer M, Su WC, Bennouna J, Kato T, Gorbunova V, Lee KH, Shah R, Massey D, Zazulina V, Shahidi M, Schuler M (2013) Phase III study of afatinib or cisplatin plus pemetrexed in patients with metastatic lung adenocarcinoma with EGFR mutations. J Clin Oncol 31:3327-3334. DOI:10.1200/JC0.2012.44.2806

10. Wu YL, Zhou C, Hu CP, Feng J, Lu S, Huang Y, Li W, Hou M, Shi JH, Lee KY, Xu CR, Massey D, Kim M, Shi Y, Geater SL (2014) Afatinib versus cisplatin plus gemcitabine for first-line treatment of Asian patients with advanced non-small-cell lung cancer harbouring EGFR mutations (LUX-Lung 6): An open-label, randomised phase 3 trial. Lancet Oncol 15:213-222. DOI:10.1016/S14702045(13)70604-1

11. Wu YL, Cheng Y, Zhou X, Lee KH, Nakagawa K, Niho S, Tsuji F, Linke R, Rosell R, Corral J, Migliorino MR, Pluzanski A, Sbar El, Wang T, White JL, Nadanaciva S, Sandin R, Mok TS (2017) Dacomitinib versus gefitinib as first-line treatment for patients with EGFR-mutationpositive non-small-cell lung cancer (ARCHER 1050): A randomised, open-label, phase 3 trial. Lancet Oncol 18:1454-1466. DOI:10.1016/S1470-2045(17)30608-3

12. Soria JC, Ohe Y, Vansteenkiste J, Reungwetwattana T, Chewaskulyong B, Lee KH, Dechaphunkul A, Imamura F, Nogami N, Kurata T, Okamoto I, Zhou C, Cho BC, Cheng Y, Cho EK, Voon PJ, Planchard D, Su WC, Gray JE, Lee SM, Hodge R, Marotti M, Rukazenkov Y, Ramalingam SS, FLAURA Investigators (2018) Osimertinib in untreated EGFR-mutated advanced non-small-cell lung cancer. N Engl J Med 378:113-125 and methods. DOI: 10.1056/NEJMoa1713137

13. Igawa S, Ono T, Kasajima M, Kusuhara S, Otani S, Fukui T, Yokoba M, Kubota M, Katagiri M, Mitsufuji H, Sasaki J, Naoki K (2020) Dec) Real-world assessment of afatinib for patients with EGFR-positive non-small cell lung cancer. Investig New Drugs 38:1906-1914. DOI:10.1007/s10637-020-00948-9

14. Ono T, Igawa S, Kurahayashi S, Okuma Y, Sugimoto A, Kusuhara S, Ozawa T, Fukui T, Sasaki J, Mitsufuji H, Yokoba M, Kubota M, Katagiri M, Naoki K (2020) Jun) Impact of neutrophil-tolymphocyte ratio in patients with EGFR-mutant NSCLC treated with tyrosine kinase inhibitors. Investig New Drugs 38:885-893. doi: 10.1007/s10637-020-00919-0. Epub 2020 Mar 10. PMID: 32157598

15. Igawa S, Ryuge S, Ichinoe M, Nakashima H, Otani S, Nakahara Y, Fukui T, Sasaki J, Kubota M, Katagiri M, Murakumo Y, Satoh Y, Sato Y, Masuda N (2017) Impact of EGFR-tyrosine kinase inhibitors on postoperative recurrent non-small-cell lung cancer harboring EGFR mutations. Oncol Res Treat 40:7-13. DOI:10.1159/000455147

16. Inoue A, Kobayashi K, Usui K, Maemondo M, Okinaga S, Mikami l, Ando M, Yamazaki K, Saijo Y, Gemma A, Miyazawa H, Tanaka T, Ikebuchi K, Nukiwa T, Morita S, Hagiwara K, North East Japan Gefitinib Study Group (2009 Mar 20) First-line gefitinib for patients with advanced non-small-cell lung cancer harboring epidermal growth factor receptor mutations without indication for chemotherapy. North East Japan gefitinib Study Group. J Clin Oncol 27:1394-1400. DOI: 
10

$.1200 / J C 0.2008 .18 .7658$

17. Okuma Y, Hosomi Y, Nagamata M, Yamada Y, Sekihara K, Kato K, Hishima T, Okamura T(2013 Nov) Clinical outcomes after first-line EGFR inhibitor treatment for patients with NSCLC, EGFR mutation, and poor performance status. Anticancer Res 33:5057-5064

18. Wu CE, Chang CF, Huang CY, Yang CT, Kuo CS, Hsu PC, Chang JW(2021 Jul 27) Feasibility and effectiveness of afatinib for poor performance status patients with EGFR-mutation-positive nonsmall-cell lung cancer. A retrospective cohort study. BMC Cancer 21:859. DOI:

10

$.1186 / s 12885-021-08587-w$

19. Nishii $Y$, Hataji $O$, Ito $K$, Watanabe F, Kobayashi T, D'Alessandro-Gabazza $C$, Toda M, Taguchi $O$, Yamamoto N, Gabazza EC(2018 Feb) Efficacy of osimertinib in a patient with non-small cell lung cancer harboring epithelial growth factor receptor exon 19 deletion/T790M mutation, with poor performance status. Mol Clin Oncol 8:246-249. DOI:

10

$.3892 /$ mco.2017.1522

20. Nakashima K, Kimura M, Akamatsu H, Daga H, Imai H, Taira T, Ko R, Hisamatsu Y, Nishino K, Sugimoto T, Miyashita Y, Takahashi T, et al (2019 Jul 1) Osimertinib for patients with EGFR T790M mutation-positive non-small-cell lung cancer and a poor performance status. Jpn J Clin Oncol 49:671-675. DOI:

10

$.1093 / j j c 0 / h y z 041$

21. Nakashima K, Ozawa Y, Daga H, Imai H, Tamiya M, Tokito T, Kawamura T, Akamatsu H, Tsuboguchi Y, Takahashi T, Yamamoto N, Mori K, Murakami H(2020 Dec) Osimertinib for patients with poor performance status and EGFR T790M mutation-positive advanced non-small cell lung cancer. $A$ phase II clinical trial. Investig New Drugs 38:1854-1861. DOI:

10

.1007/s10637-020-00943-0

22. Siegel R, DeSantis C, Virgo K, Stein K, Mariotto A, Smith T, Cooper D, Gansler T, Lerro C, Fedewa S, Lin C, Leach C, Cannady RS, Cho H, Scoppa S, Hachey M, Kirch R, Jemal A, Ward E (2012) Cancer treatment and survivorship statistics, 2012. CA Cancer J Clin 62:220-241. DOI:10.3322/caac.21149

23. Ohe $Y$, Imamura F, Nogami N, Okamoto I, Kurata T, Kato T, Sugawara S, Ramalingam SS, Uchida H, Hodge R, Vowler SL, Walding A, Nakagawa K (2019) Osimertinib versus standard-of-care EGFR-TKI as first-line treatment for EGFRm advanced NSCLC: FLAURA Japanese subset. Jpn J Clin Oncol 49:29-36. DOI:10.1093/jjco/hyy 179

24. Gemma A, Kusumoto M, Sakai F, Endo M, Kato T, Saito Y, Baba T, Sata M, Yamaguchi O, Yabuki Y, Nogi Y, Jinushi M, Sakamoto K, Sugeno M, Tamura R, Tokimoto T, Ohe Y (2020) Real-world evaluation of factors for interstitial lung disease incidence and radiologic characteristics in patients 
with EGFR T790M-positive NSCLC treated with Osimertinib in Japan. J Thorac Oncol 15:1893-1906. DOI:10.1016/j.jtho.2020.08.025

25. Mok TS, Wu Y-L, Ahn M-J, Garassino MC, Kim HR, Ramalingam SS, Shepherd FA, He Y, Akamatsu H, Theelen WS, Lee CK, Sebastian M, Templeton A, Mann H, Marotti M, Ghiorghiu S, Papadimitrakopoulou VA, AURA3 Investigators (2017) Osimertinib or platinum-pemetrexed in EGFR T790M-positive lung cancer. N Engl J Med 376:629-640. DOI:10.1056/NEJMoa1612674

26. Yang JC-H, Ahn MJ, Kim DW, Ramalingam SS, Sequist LV, Su WC, Kim SW, Kim JH, Planchard D, Felip E, Blackhall F, Haggstrom D, Yoh K, Novello S, Gold K, Hirashima T, Lin CC, Mann H, Cantarini M, Ghiorghiu S, Jänne PA (2017) Osimertinib in pretreated T790M-positive advanced non-small-cell lung cancer: AURA study phase II extension component. J Clin Oncol 35:1288-1296.

DOI:10.1200/JC0.2016.70.3223

\section{Tables}

Table 1.

\begin{tabular}{ll} 
& $\mathrm{n}=16(\%)$ \\
\hline Age (years), median, range & $78(54-89)$ \\
\hline $\begin{array}{l}\text { Gender } \\
\text { Male/Female }\end{array}$ & $9(56) / 7(44)$ \\
\hline Performance status & $14(88) / 2(12)$ \\
$2 / 3$ & \\
\hline EGFR genotype & $10(62) / 6(38)$ \\
\hline Del 19/L858R & $14(88) / 2(12)$ \\
\hline Histology & \\
Adenocarcinoma/Adeno-squamous & $12(75) / 4(25)$ \\
\hline Stage & \\
IV/Recurrence & $9(56) / 7(44)$ \\
\hline Smoking status & \\
Smoker/Never smoker & $9(56) / 7(44)$
\end{tabular}

Table 2. 


\begin{tabular}{ll} 
& $\mathrm{n}=16$ \\
\hline Complete response & 0 \\
\hline Partial response & 9 \\
\hline Stable disease & 4 \\
\hline Progressive disease & 3 \\
\hline Response rate & $56.3 \%$ \\
\hline $95 \% \mathrm{Cl}$ & $47.1-78.0$
\end{tabular}

Table 3.

\begin{tabular}{|c|c|c|c|c|c|}
\hline Adverse event & Any Grade (\%) & Grade $1(\%)$ & Grade 2 (\%) & Grade $3(\%)$ & Grade $4(\%)$ \\
\hline Rash acneiform & $7(44)$ & $5(31)$ & $2(13)$ & 0 & 0 \\
\hline Diarrhea & $6(38)$ & $5(31)$ & $1(6)$ & 0 & 0 \\
\hline Paronychia & $6(38)$ & $6(38)$ & 0 & 0 & \\
\hline Oral mucositis & $4(24)$ & $4(24)$ & 0 & 0 & 0 \\
\hline Anorexia & $4(24)$ & $2(18)$ & $2(12)$ & 0 & 0 \\
\hline Fatigue & $4(24)$ & $2(18)$ & $1(6)$ & $1(6)$ & \\
\hline Nausea & $3(18)$ & $2(12)$ & $1(6)$ & 0 & \\
\hline Dry skin & $2(12)$ & $2(12)$ & 0 & 0 & \\
\hline Constipation & $2(12)$ & $2(12)$ & 0 & 0 & \\
\hline Tinnitus & $1(6)$ & $1(6)$ & 0 & 0 & \\
\hline Neutropenia & $7(44)$ & $6(38)$ & $1(6)$ & 0 & 0 \\
\hline Leukopenia & $7(44)$ & $5(31)$ & $2(12)$ & 0 & 0 \\
\hline Anemia & $4(24)$ & $2(12)$ & $1(6)$ & $1(6)$ & 0 \\
\hline Thrombocytopenia & $3(18)$ & $3(18)$ & 0 & 0 & 0 \\
\hline Creatinine increased & $3(18)$ & $2(18)$ & $1(6)$ & 0 & 0 \\
\hline AST/ALT increased & $3(18)$ & $2(12)$ & $1(6)$ & 0 & 0 \\
\hline QTc prolongation & $1(6)$ & $1(6)$ & 0 & 0 & 0 \\
\hline Interstitial lung disease & $2(12)$ & 0 & $1(6)$ & $1(6)$ & 0 \\
\hline
\end{tabular}

Table 4. 
Drug No. of Pts. ${ }^{a} \quad$ Study design Response rate Median PFS ${ }^{b}$

(\%) (months)

\begin{tabular}{llllll}
\hline Inoue (16) & GEF & 31 & Prospective & 66.0 & 6.5 \\
\hline Okuma (17) & GEF $^{\mathrm{C}}$ & 52 & Retrospective & 65.4 & 6.6 \\
\hline Wu (18) & AFA $^{\mathrm{d}}$ & 62 & Retrospective & 58.1 & 8.8 \\
\hline Present study & OSIM $^{\mathrm{e}}$ & 16 & Prospective & 56.3 & 10.5
\end{tabular}

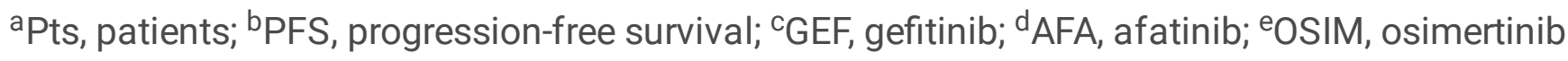

Figures

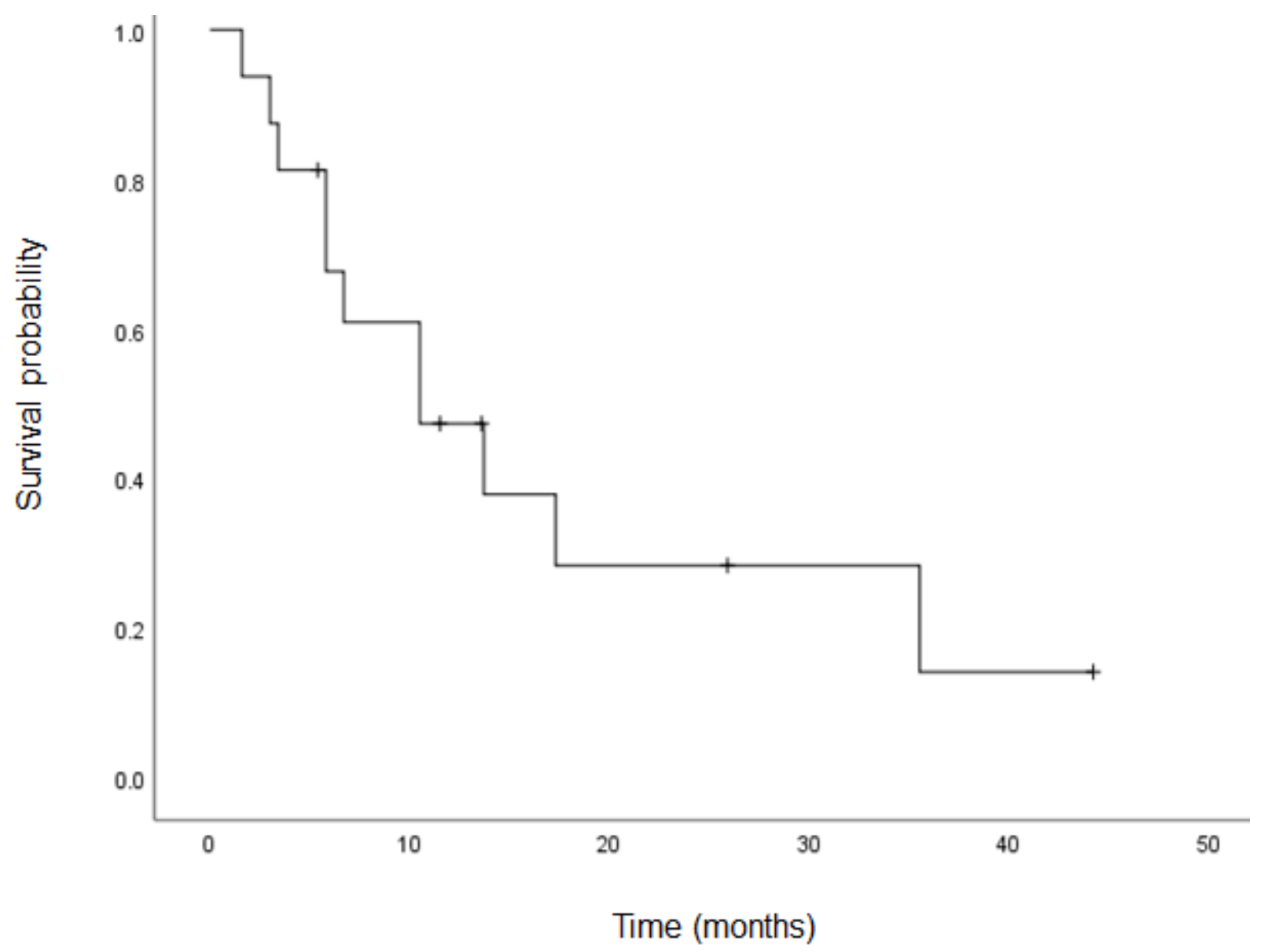

Figure 1

Kaplan-Meier curves showing the progression-free survival to osimertinib therapy 


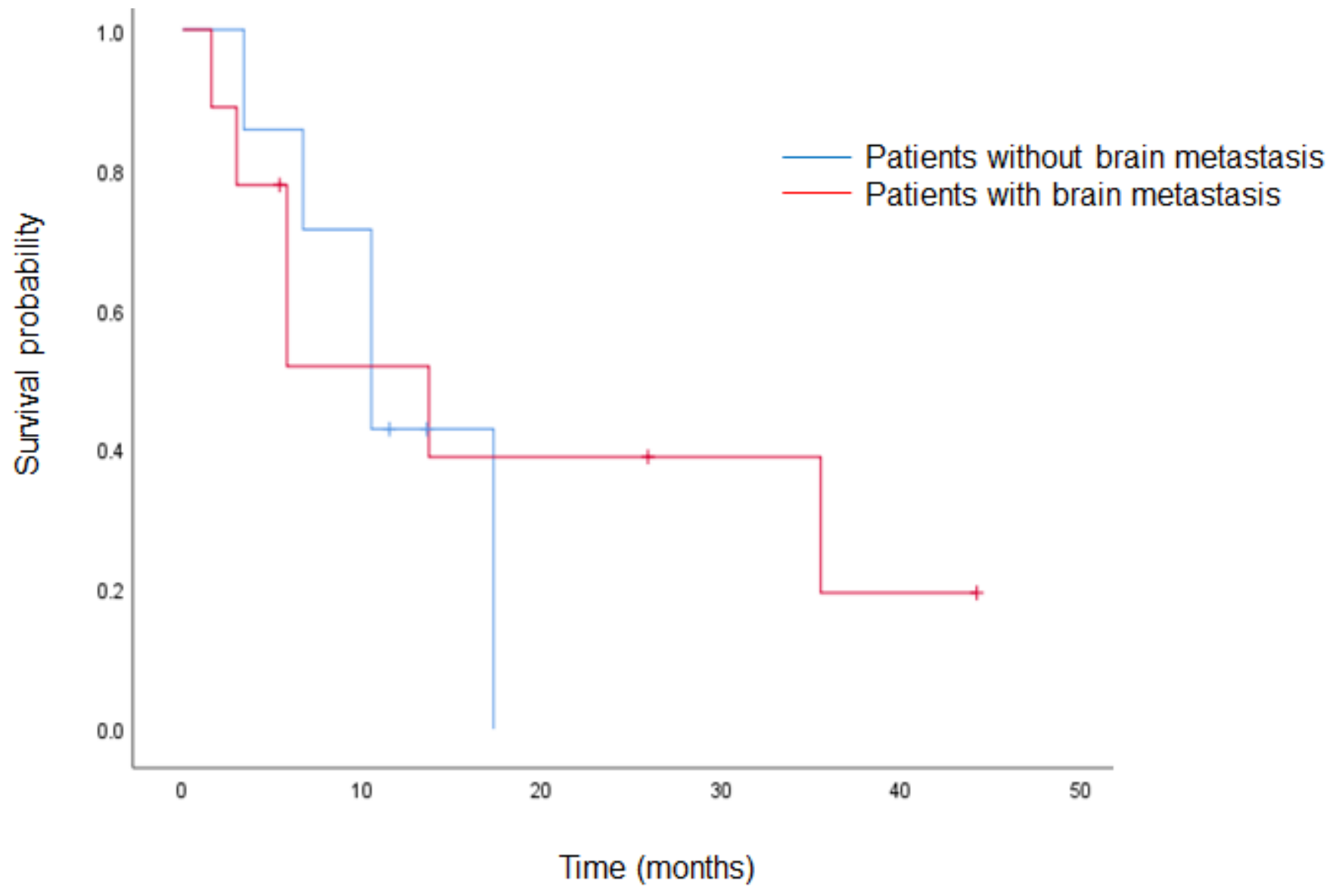

Figure 2

Kaplan-Meier curves showing the progression-free survival of patients with versus without pre-existing brain metastasis 


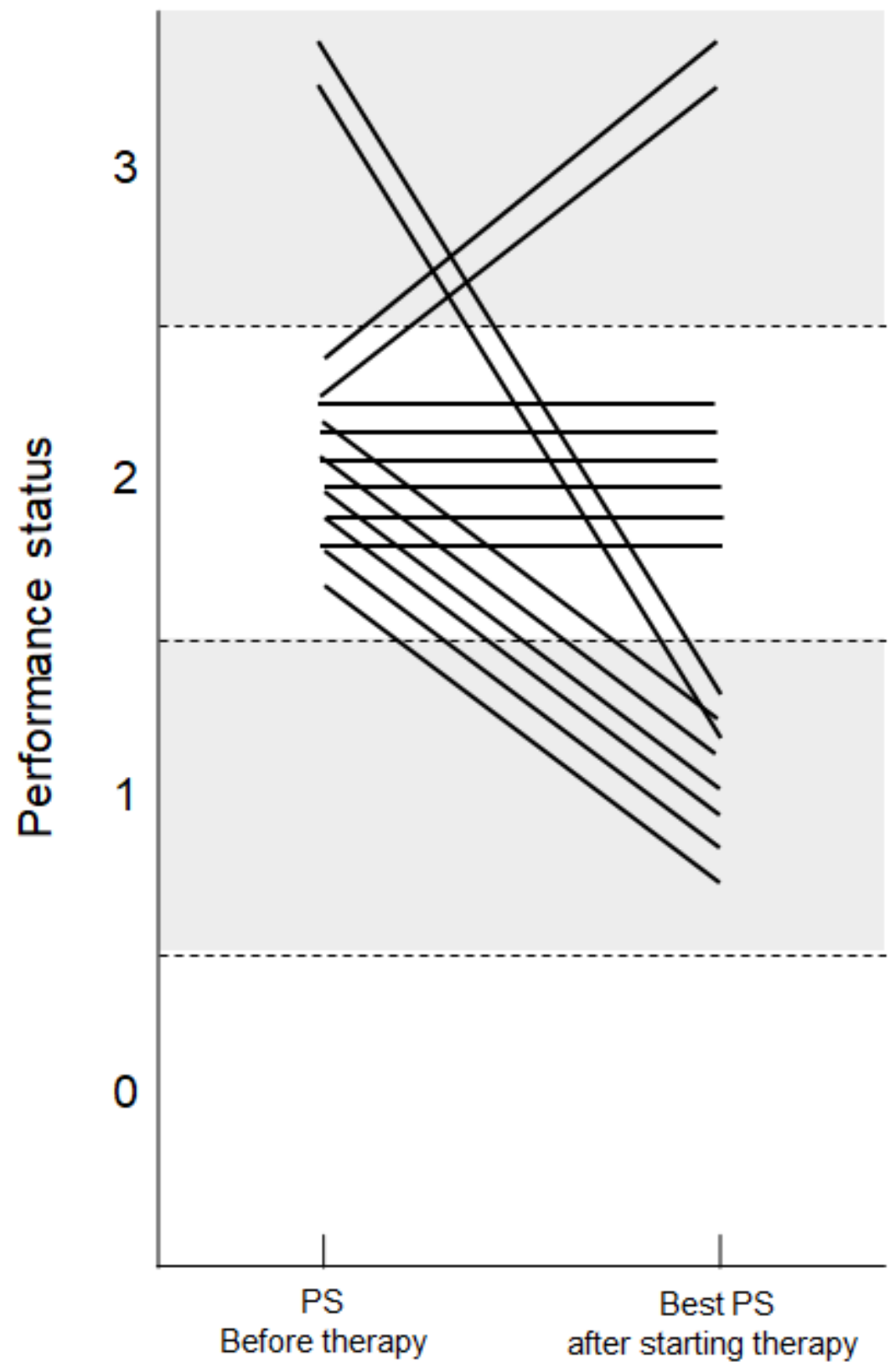

Figure 3

The overall changes in the PS scores of all patients during osimertinib treatment 


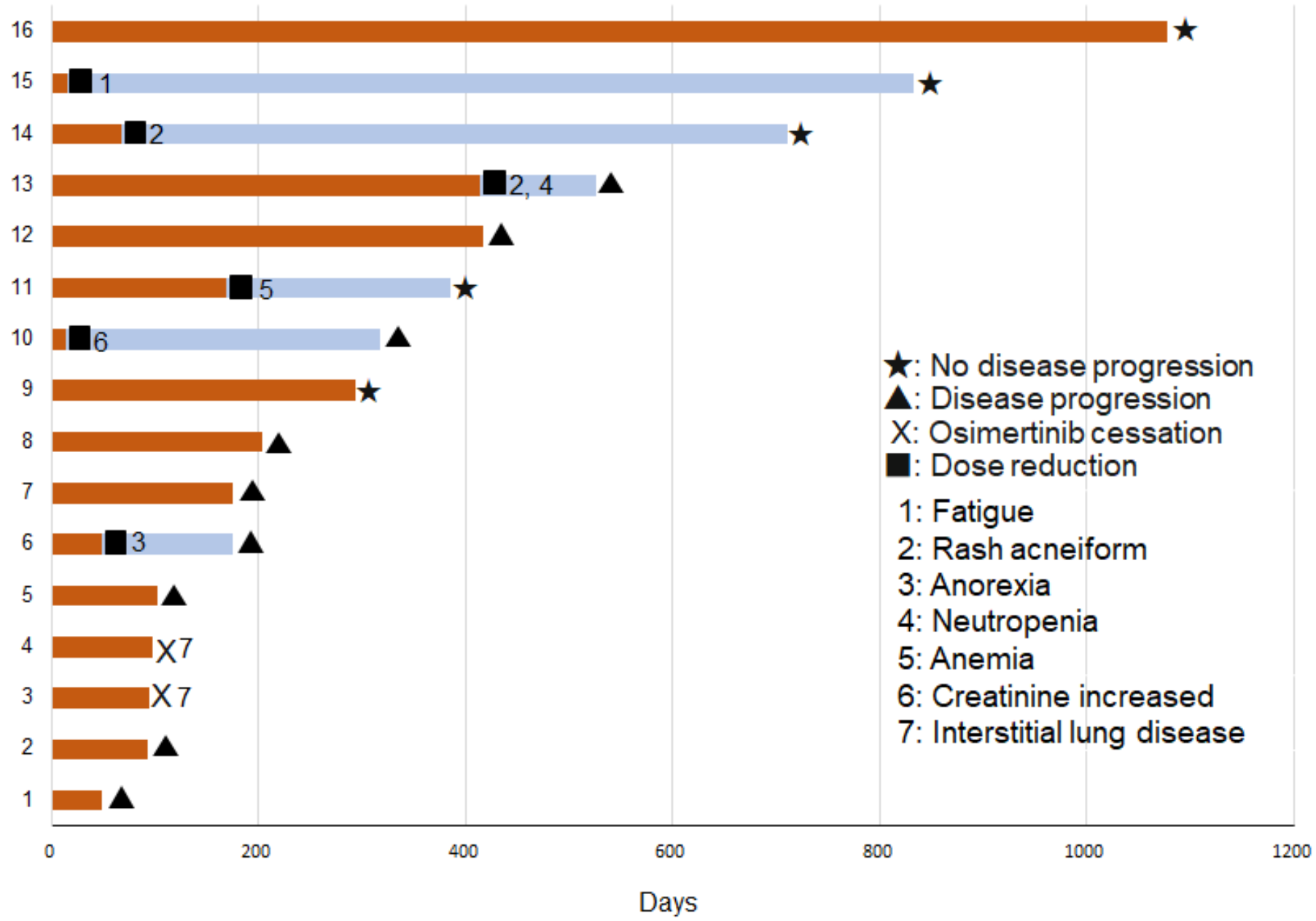

Treatment duration of osimertinib in the safety analysis set

Figure 4

Duration of osimertinib treatment before disease progression or cessation owing to adverse events in individual patients 